\title{
UM ESTUDO TEÓRICO DE SIGNETEMAS NA LÍNGUA BRASILEIRA DE SINAIS: REFLEXÕES INICIAIS \\ ****
}

\author{
A THEORETICAL STUDY OF SIGNETHEMAS IN THE \\ BRAZILIAN SIGN LANGUAGE: INITIAL REFLECTIONS
}

\author{
Charley Pereira Soares
}

Recebimento do texto: 19/04/2018

Data de aceite: 25/05/2018

\begin{abstract}
RESUMO: A iconicidade dos signos linguísticos já é algo conhecido tanto nas línguas de modalidade espaço-visual quanto nas línguas de modalidade oral-auditiva. A semelhança, de cunho linguístico-descritivo, entre o simbolismo oral e o simbolismo visual também é reconhecida na literatura da área. Nas línguas de sinais, componentes como configuração de mão ou ponto de articulação podem expressar um conteúdo comum a determinado grupo de sinais, que chamamos famílias lexicais, e expressam o papel do simbolismo sonoro (gestual) no surgimento de novos signos. Dessa forma, o objetivo deste trabalho é evidenciar grupos de signetemas em algumas famílias de signos na Língua Brasileira de Sinais (Libras), buscando descrever sinais que se relacionam formal e semanticamente por meio de determinados parâmetros fonológicos. Em caráter inicial de pesquisa, identificou-se alguns sinais que foram categorizados a partir de padrões observados na sua constituição sigmanulogica e semântica.
\end{abstract}

PALAVRAS-CHAVE: Família lexical; Libras; Semântica; Signetemas; Simbolismo gestual.

ABSTRACT: Iconicity of linguistics signs is generally known for both languages modalities: visual as a spatial gestures and oral speech. The similarity between oral symbolism and symbolism in sign languages can be recognized in the linguistic field. In the signal language, components such as hand configuration or localization can be expresses a common content to a certain group of signals. For example, it can express lexical families and the role of listening symbolism in the appearance of new signs. Then, the aim of this paper is identify groups of signetemas in some families of signs in the Brazilian Sign Language (Libras), aiming to describe signs that are related formally and semantically through certain phonological parameters, such as hands' configuration, articulation position, movement, hand orientation, and non-manual expressions. In the initial investigation of this research, we identified some signals that were categorized from the patterns observed in their sigmanulogical and semantic constitution.

KEYWORDS: Lexical association group; Brazilian Sign Language; Semantic; Signetemas; Gestural Symbolism.

\footnotetext{
${ }^{1}$ Doutorando em Linguística na Universidade Federal de Santa Catarina/ UFSC, com minha orientadora Dra. Ronice Müller de Quadros, e docente da Universidade Federal de Viçosa / UFV, charley.psoares@ gmail.com
} 


\section{Introdução}

Simbolismo sonoro é um conceito normalmente aplicado a línguas orais e representa um aspecto da iconicidade linguística. Nessas línguas, o simbolismo sonoro envolve onomatopeias e os chamados símbolos sonoros ou fonestemas. Este último fenômeno corresponde, nessas línguas, a grupos de fonemas que, sem se encaixarem na definição clássica de morfema, muitas vezes evocam uma noção de natureza mais vaga que constitui o significado de diversas palavras que contém tais fonemas (ULLMANN, 1962, p. 17-24). Dessa forma, a noção de simbolismo sonoro ou fonestesia, é de interesse da fonética, da estilística e da semântica.

Neste trabalho, abordamos o conceito de fonestemas em sua aplicação à Língua Brasileira de Sinais. Nosso propósito é descrever sinais que se relacionem formal e semanticamente, por meio de determinados parâmetros clássicas sigmanulogia ${ }^{2}$ como configuração de mãos, ponto de articulação, movimento, orientação da palma da mão e expressões nãomanuais.

Sabendo disso, iniciamos nosso texto tratando da caracterização desses conceitos em sua relação com as línguas orais e do seu papel na iconicidade linguística. Em seguida, focamos na definição de signetemas quando aplicados a línguas de sinais em específico na Libras.

2 Nesse trabalho utilizamos a palavra fonológico seguindo os padrões nacionais e internacionais que discutem esse nível linguístico nas línguas de sinais e nas línguas orais. Contudo, no Brasil, há uma recente proposta feita pelo professor Valdo Nóbrega (2016) para que os estudos no âmbito da fonologia sejam denominados de sigmanulogia, fazendo menção ao signo e a modalidade visuo-espacial dessas línguas. 
Em línguas de sinais os signetemas seriam associações ou relações estabelecidas entre articuladores visuais como os parâmetros formas sinais, a um determinado conceito, se repetindo em vários sinais que fazem alusão a esse mesmo sentido (RATHMANN; MATHUR, 2010?; HEALY, 2011). Ao reconhecer essas similaridades semânticas existentes entre os sinais, pode-se obter a chamada família lexical. No Brasil, pesquisas dessa natureza ainda são incipientes, o que justifica nossa iniciativa. Caso nos debrucemos em estudos nessa linha, poderemos encontrar, talvez, promissoras perspectivas quanto a aspectos lexicológicos e lexicográficos na/para Libras.

\section{Iconicidade e simbolismo sono nas línguas orais}

Apesar de descartada por Ferdinand de Saussure (1991 [1916]) em sua conhecida defesa da "arbitrariedade do signo linguístico", a iconicidade já há algum tempo parece ser uma questão resolvida e aceita, como afirma Ullmann (1977 [1964], p. 169), ao observar que todo idioma apresenta signos "arbitrários e opacos" e outros "até certo grau, motivados e transparentes".

Um símbolo sonoro ou fonestemas diz respeito à associação sinestésica entre um som ou cadeia de sons linguísticos a um determinado conteúdo conotativo, cadeia essa que se repete em várias palavras que compartilham essa noção. Uma menção a esse aspecto particular da iconicidade linguística já podia ser encontrado no diálogo Crátilo, de Platão (c. 429-347 a. C.), para explicar a motivação por trás dos "nomes originais", 
a qual não poderia ser justificada por meio da etimologia (Weedwood, 2005, p. 24-26). Um exemplo do grego retirado do famoso diálogo é o fonema [1], que representa a ideia de deslizar ou resvalar, um significado que está presente nas formas gregas liparón (liso), glyký(doce) e glískeron (viscoso).

Bloomfield (1961 [1933], p. 244-245) identifica essas cadeias como "morfemas formadores de radicais (root-forming morphemes) de significação vaga", os quais, como demonstram seus exemplos na língua inglesa, podem ocorrer no início ou no fim do radical. Alguns exemplos de sequências em posição inicial são: [fl-] 'luz em movimento': flash (clarão súbito), flare, flame, flick-er, flimm-er. [gl-] 'luz estática': glow, glare, gloat, gloom (gleam, gloam-ing, glimm-er), glint. [sn-] 'separação ou movimento rápido': snap (snip), snatch (snitch). Exemplos de sequências em posição final no inglês são: [-ejr] 'grande luz ou ruído': blare, flare, glare, stare. [-awns] ' movimento rápido': bounce, jounce, pounce, trounce. [-omp] 'desajeitado': bump, clump, chump, dump, frump, hump, lump, rump, stump, slump, thump.

Entretanto, de acordo com o mesmo autor, essas "raízes simbólicas" diferem do padrão morfológico da língua inglesa no tocante à coexistência de sons semelhantes no radical e no sufixo. Apenas itens com essas sequências simbólicas obedecem a um princípio segundo o qual a presença de $[r]$ no radical impede a ocorrência de um sufixo [-r] e, igualmente, a presença de um [1] anterior não permite a ocorrência de um [1] como sufixo. Segundo esse autor, brabble (discutir em voz alta, altercar) e blabber (falar excessivamente, sem nexo) são palavras com raízes 
simbólicas no inglês, em contraste com *brabber ou *blabble, inexistentes nesse idioma.

Assim, como as onomatopeias, fonestemas formam um tipo de indutores fonéticos (phonetic elicitors) de traços semânticos (Cruse, 1986, p. $35 ; 46)$, mas distinguem-se daquelas em função do tipo de iconicidade que representam e da sua produtividade na língua.

As onomatopeias são expressões que contém ou consistem de sons que apresentam semelhanças em termos de percepção auditiva com os seus referentes na realidade (Cruse, 1986, p. 34). Exemplos conhecidos são nomes de pássaros ou de artefatos, formados por sequências que imitam o som que esses seres produzem - "quero-quero", "reco-reco", ou verbos como "tilintar", contendo fonemas que reproduzem o som de sinos ou campainhas, "miar", que imita a voz de um gato. São, portanto, morfemas livres, simples ou complexos. A iconicidade nessas expressões depende, então, do meio fônico e, por isso, é considerada iconicidade primária (igualmente a Lyons (1984, p. 103), com base no termo onomatopeia primária, preferido por Ullmann (1977 [1964], p. 175) em contraste com a onomatopeia secundária ou iconicidade secundária, que aqui chamamos de fonestemas.

Sob esse aspecto, o simbolismo sonoro se distingue por apresentar um tipo de iconicidade secundária (Lyons, 1984, p. 104), tendo em vista que, nesse caso, “o lexema [contendo um fonestemas] não denota um som ou a fonte de um som”. Por exemplo, destaca Ullmann (p. 182), em vários idiomas, a vogal |i| está presente em muitos substantivos e adjetivos que evocam a ideia de pequenez, como petit do francês, little e wee do inglês, 
kicsi no húngaro. Ainda assim, como explica esse autor, podem ser apontados outros tantos contraexemplos, como big e small (respectivamente, "grande" e "pequeno" no inglês), apró ("fino", "miúdo" em húngaro) ou Riese ("gigante" em alemão").

É importante salientar, contudo, que na maioria das vezes, a presença de um fonema como |i| não está associada a nenhum sentido que permita a identificação de iconicidade primária ou secundária. Nesse caso, o som permanece neutro e "a palavra será opaca e inexpressiva".

A expressão símbolo sonoro parece ser controverso quando se para Abelin (1999), o adjetivo sound symbolic se refere a expressões que apresentam, em sua estrutura sonora, algum tipo de motivação semântica, tais como onomatopeias. Essa definição distingue-se daquela de símbolo apresentada por Pierce (1955), cuja principal diferença em relação ao índice e ao ícone está justamente na arbitrariedade do primeiro.

\section{Pressupostos teóricos referentes às famílias lexicais em língua de sinais}

Rathmann e Mathur (2010?), ponderam que as famílias lexicais são grupos de sinais que compartilham da mesma especificação para um ou mais parâmetros fonológicos e se enquadram em uma mesma categoria semântica. Por isso, essa denominação pode ser estendida a todas as línguas de sinais, evidenciando certas semelhanças entre elas. Para exemplificação, recorremos a alguns léxicos da Língua de Sinais Britânia (BSL) ${ }^{3}$

${ }^{3}$ Os sinais da BSL, bem como de várias outras línguas de sinais podem ser encontrados no site https://www.spreadthesign.com/br/ ou de aplicativos do 
apresentados por Rathmann e Mathur (2010?), em que os sinais da primeira coluna têm uma mesma configuração de mão em caráter semântico positivo. Na segunda coluna, os sinais possuem, entre si, uma mesma configuração de mão expressando uma ideia de negatividade. Nesse caso, essas configurações serão as bases.

\begin{tabular}{|l|l|}
\hline Positivo & Negativo \\
\hline CONGRATULATE & CRITICIZE \\
RIGHT & WRONG \\
GOOD & BAD \\
\hline
\end{tabular}

Outro exemplo que os autores supracitados comentam e merece destaque é em relação a Língua de Sinais Americana (ASL). A seguir, há o esboço de um quadro com um tipo de família lexical baseada no gênero, onde os sinais referentes ao sexo feminino são realizados do nariz para baixo e os sinais referentes ao sexo masculino são produzidos do nariz para cima. Isso demonstra que o parâmetro localização é a base desse grupo de sinais.

\begin{tabular}{|l|l|}
\hline Feminino & Masculino \\
\hline WOMAN & MAN \\
MOTHER & FATHER \\
\hline
\end{tabular}

mesmo endereço eletrônico. 


\begin{tabular}{|l|l|}
\hline DAUGHTER & SON \\
GRANDMOTHER & GRANDFATHER \\
SISTER & BROTHER \\
\hline & \\
\hline
\end{tabular}

\section{Aspectos metodológicos e caracterização dos dados}

Para condução desse trabalho, apoiamo-nos em perspectivas que se baseiam na pesquisa qualitativa. De acordo com Minayo (2001), esse tipo de pesquisa não se atenta especificamente apenas a números e percentagens, mas busca descrever, entender e elucidar relações e situações dinâmicas e sociais.

Seguindo essa direção, o corpus aqui elaborado é proveniente de acesso ao Glossário do curso Letras/Libras da Universidade Federal de Santa Catarina (UFSC), além do registro livre obtido por enunciações de surdos sinalizantes via observação direta. Esse caminho foi traçado por nós, autores, pelo fato de reconhecermos a possiblidade da existência dos signetemas também na Libras.

\section{Análise e descrição dos signetemas na língua brasileira de sinais}

A seguir será apresentada algumas famílias lexicais identificadas na Libras, onde há um ou mais parâmetros sigmanulogia em comum compartilhando da mesma ideia semântica. 
ISSN: 2316-3933

Online

REVISTA ECOS

Programa de Pós-graduação em Estudos Literários/ UNEMAT

Programa de Pós-graduação em Linguística/ UNEMAT

Centro de Estudos e Pesquisas em Literatura

Centro de Estudos e Pesquisas em Linguagem

No primeiro conjunto de exemplos, percebe-se que o movimento é um parâmetro em comum trazendo uma perspectiva de formação/constituição de um grupo e/ou aglomerado de pessoas.
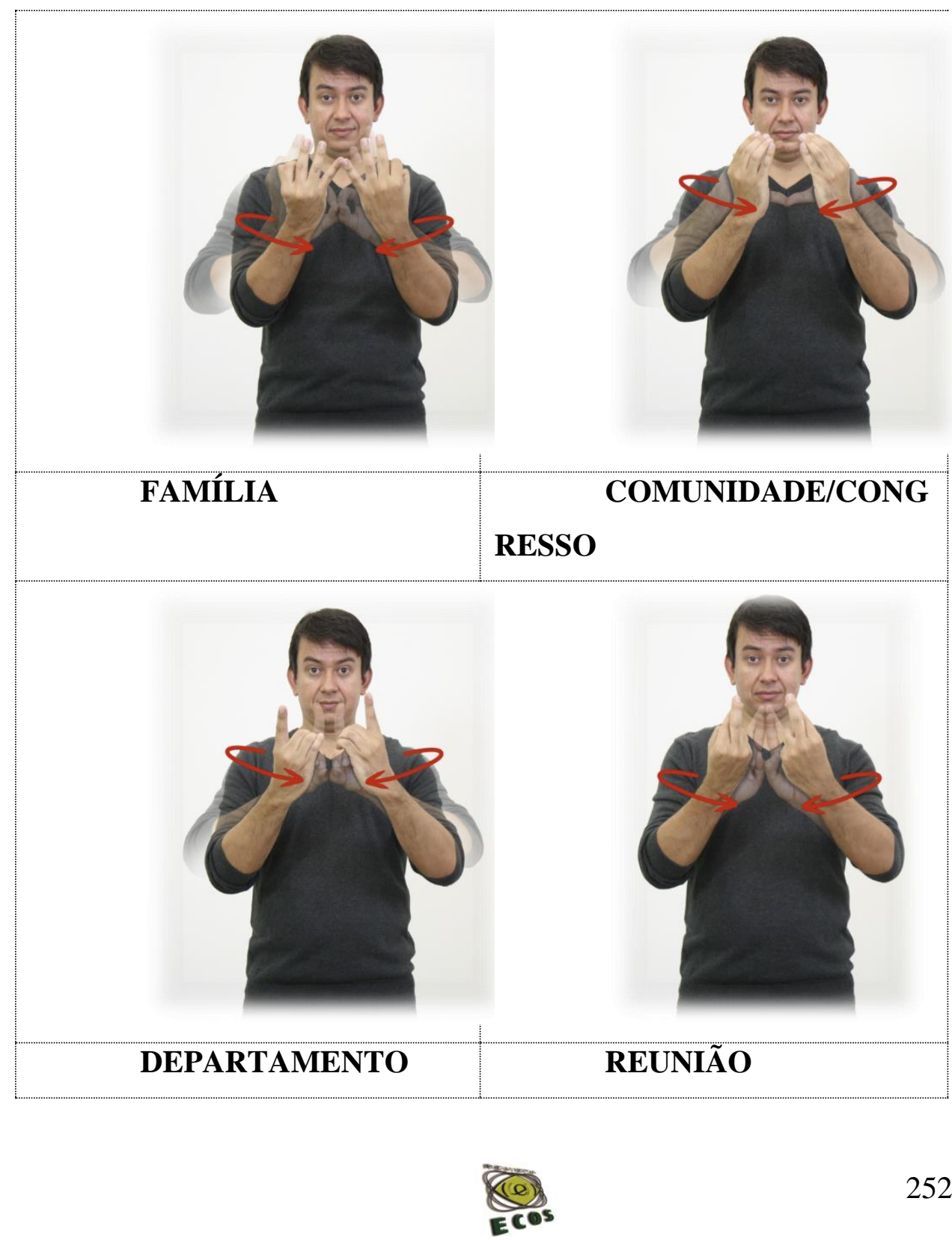
No segundo exemplo, tem-se uma família lexical que compartilha a mesma configuração de mão e, em alguns casos, o mesmo movimento. $\mathrm{O}$ sentido se refere a registros escritos.

ARTIGO-LEI CARRICULO COITULO)


ISSN: 2316-3933

Online

\section{REVISTA ECOS}

Programa de Pós-graduação em Estudos Literários/ UNEMAT

Programa de Pós-graduação em Linguística/ UNEMAT

Centro de Estudos e Pesquisas em Literatura

Centro de Estudos e Pesquisas em Linguagem
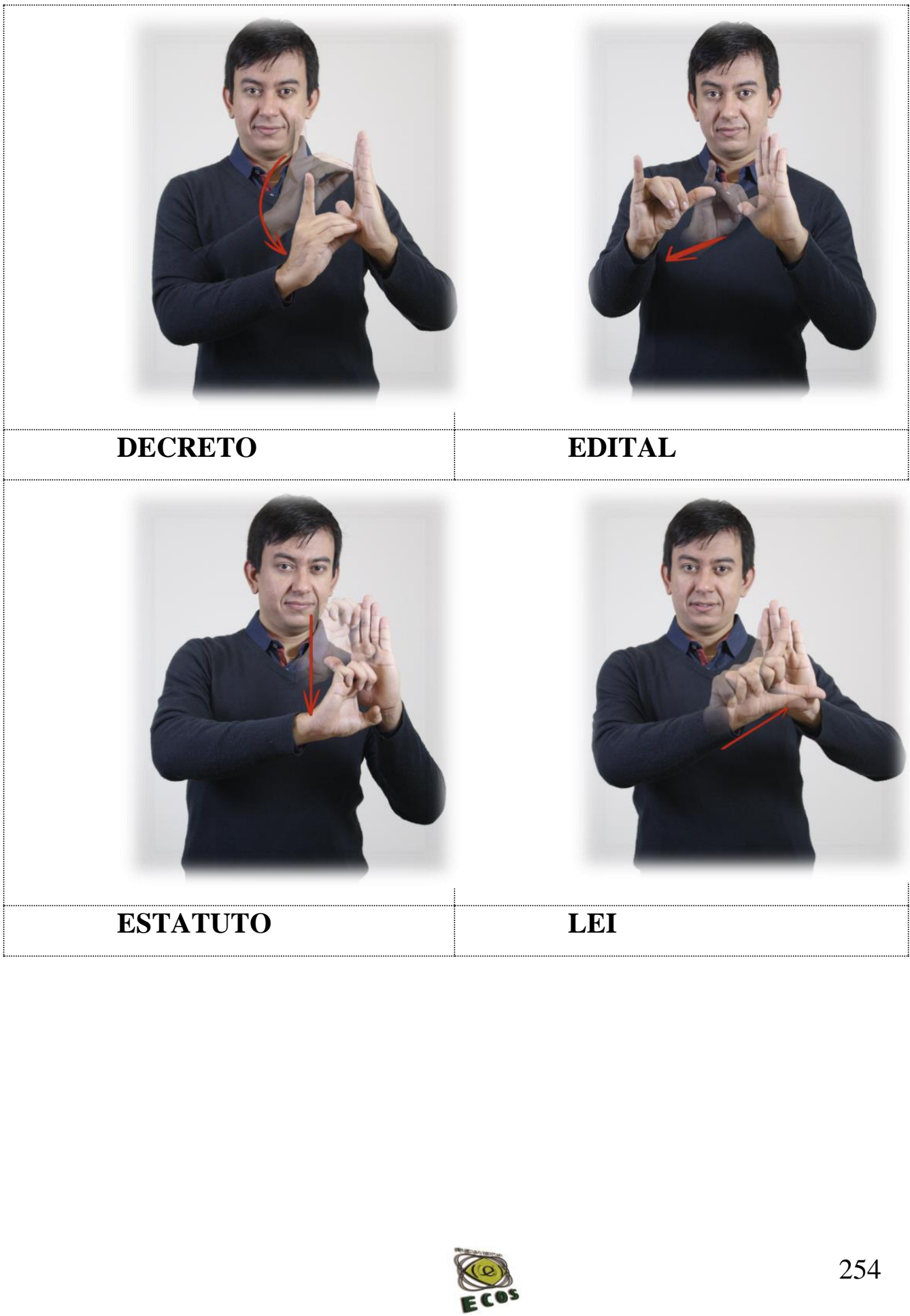
ISSN: 2316-3933

Online

\section{REVISTA ECOS}

Programa de Pós-graduação em Estudos Literários/ UNEMAT

Programa de Pós-graduação em Linguística/ UNEMAT

Centro de Estudos e Pesquisas em Literatura

Centro de Estudos e Pesquisas em Linguagem
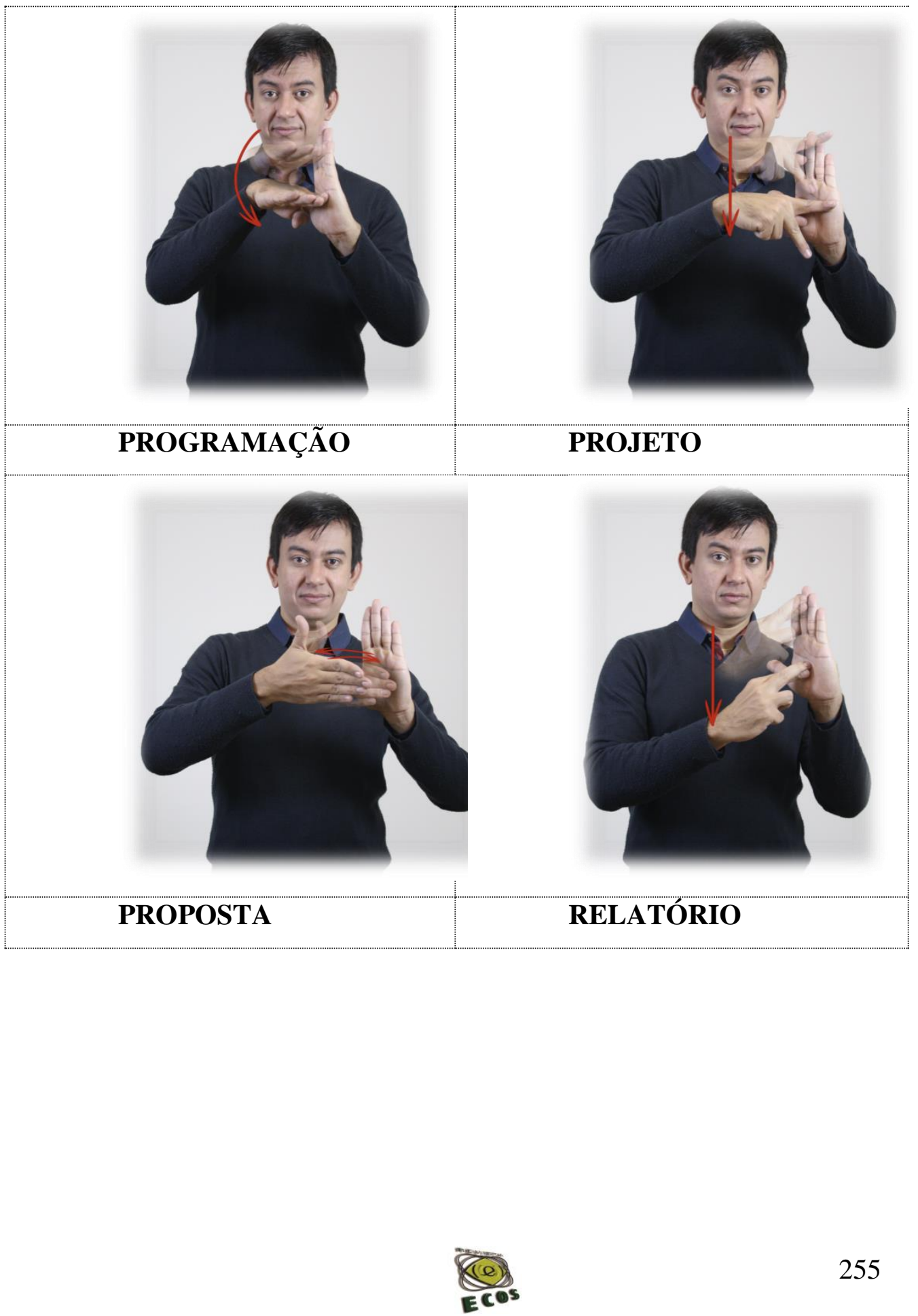


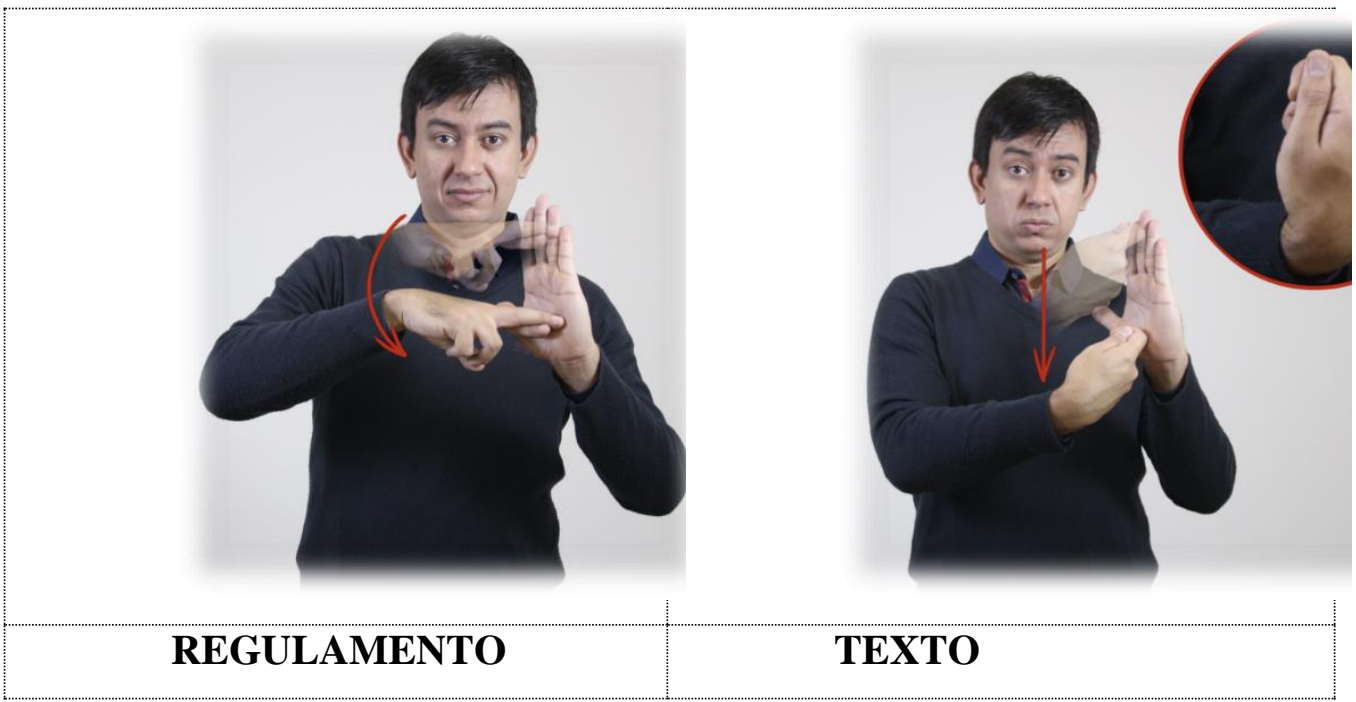

No terceiro exemplo de família lexical, encontra-se uma mesma configuração de mão utilizada pelos sinais com sentido relacionado a unidades linguísticas (significativa).
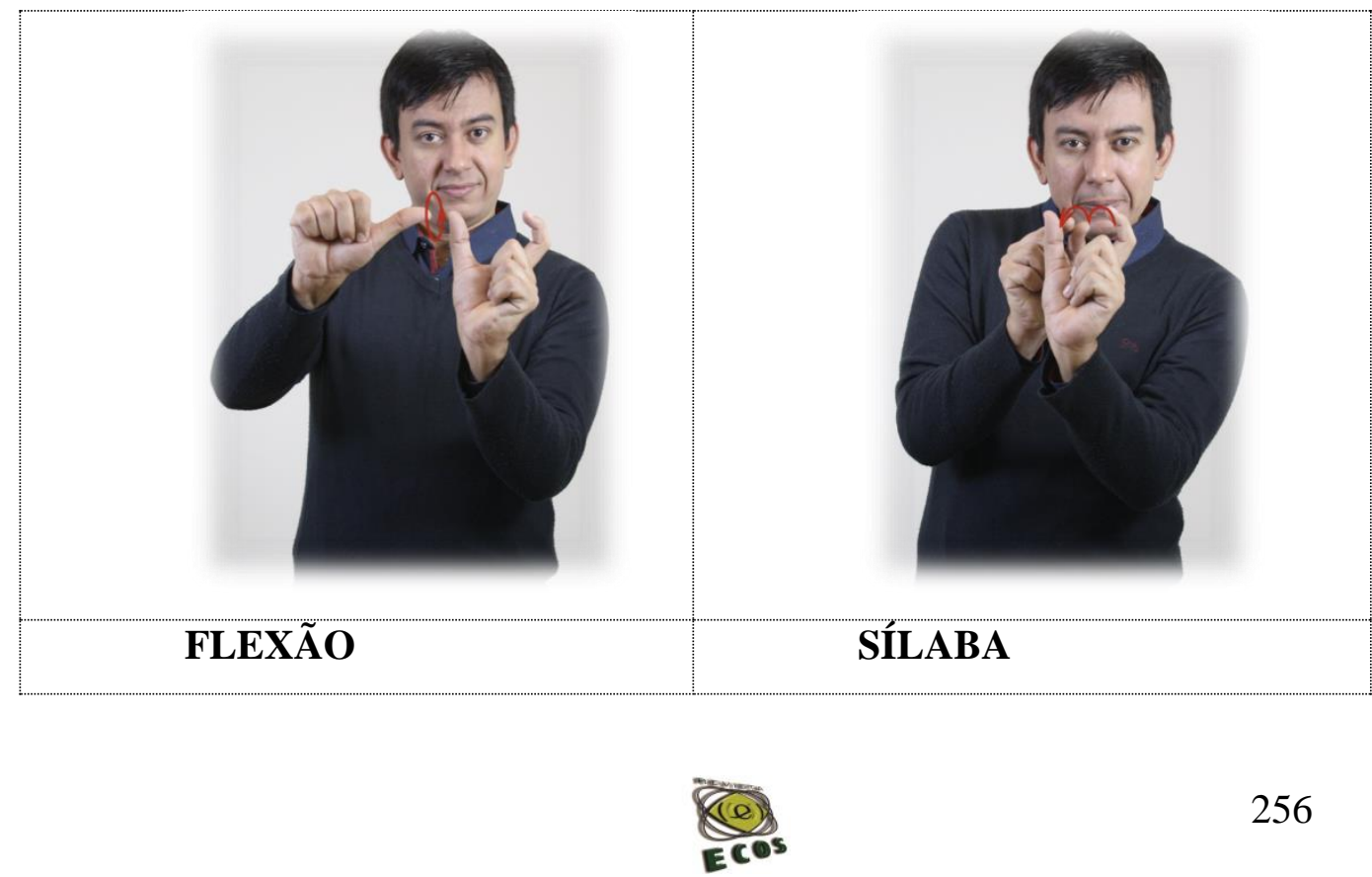
ISSN: 2316-3933

Online

\section{REVISTA ECOS}

Programa de Pós-graduação em Estudos Literários/ UNEMAT

Programa de Pós-graduação em Linguística/ UNEMAT

Centro de Estudos e Pesquisas em Literatura

Centro de Estudos e Pesquisas em Linguagem
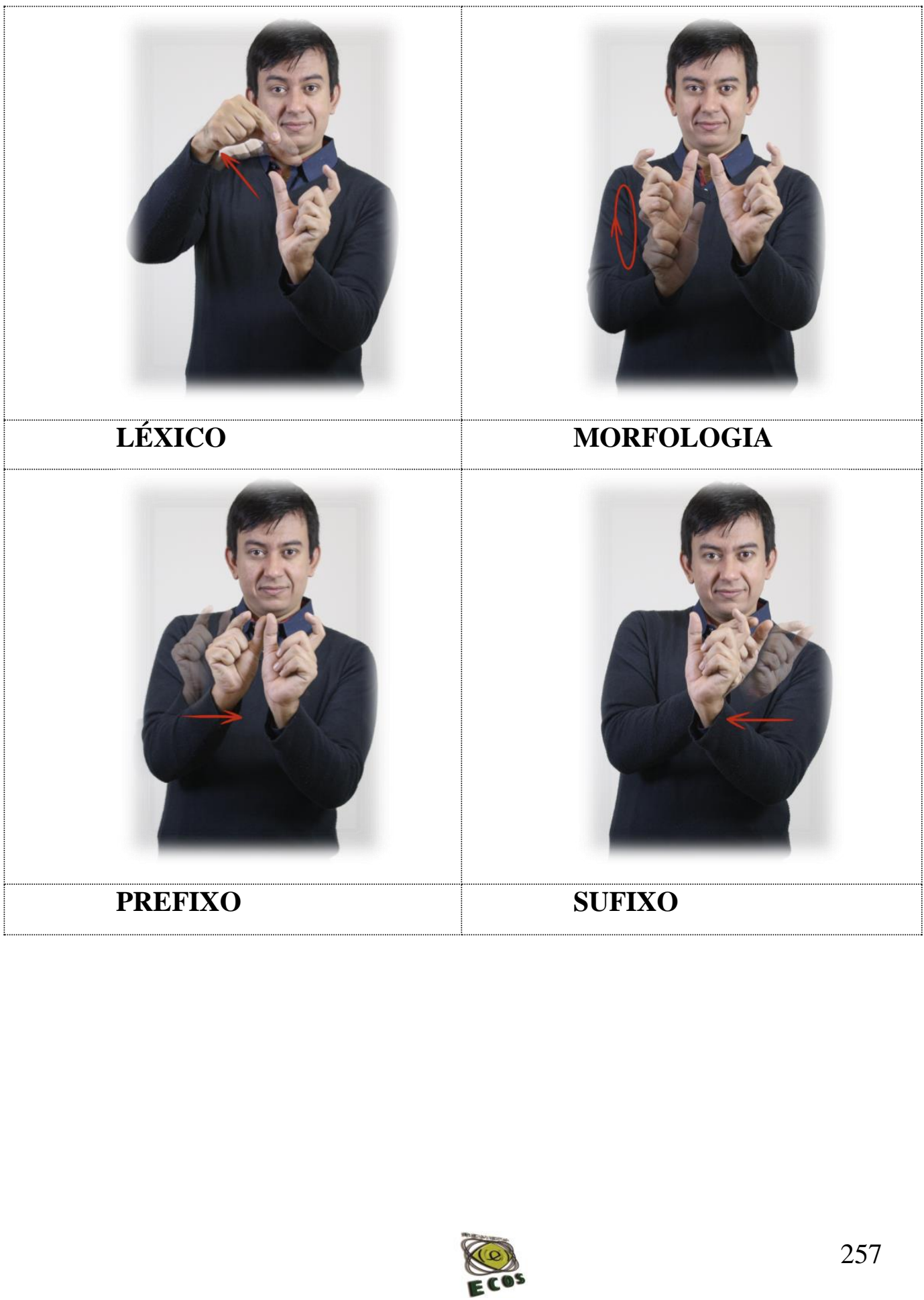


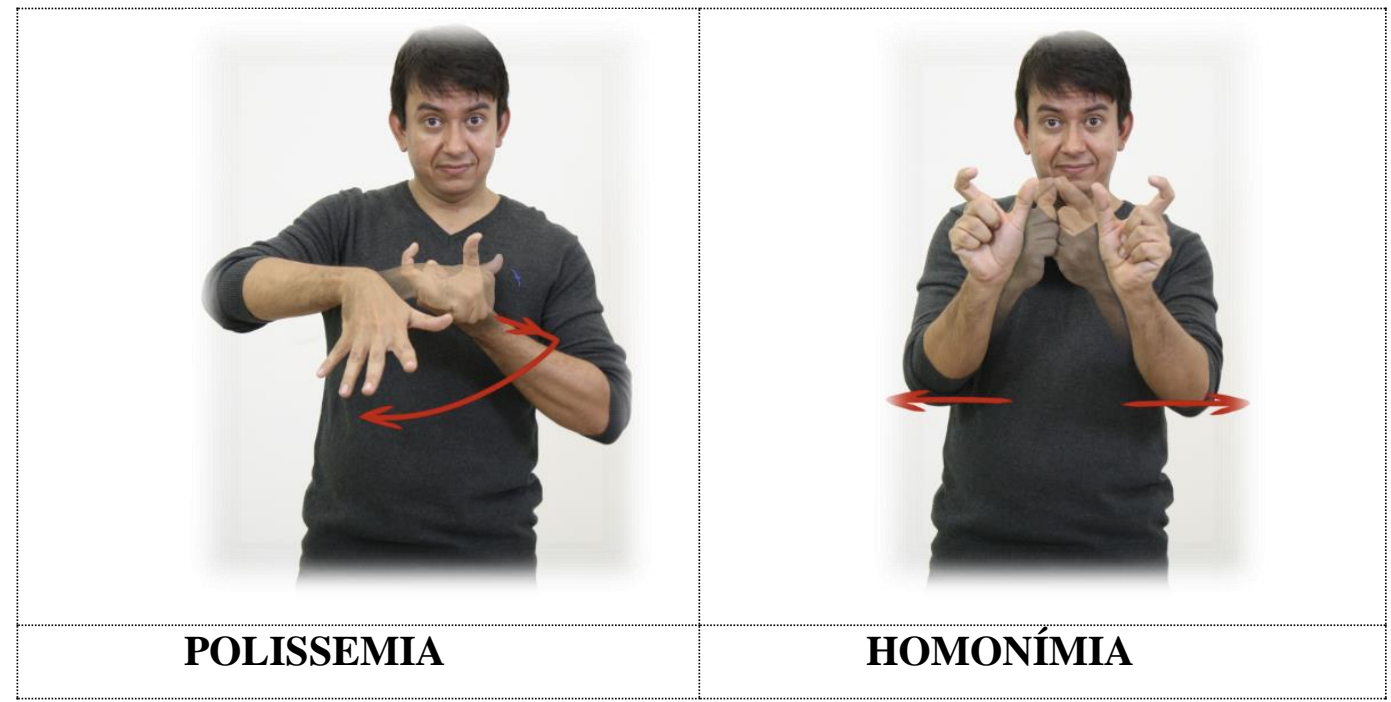

No próximo exemplo, a família lexical identificada faz uso de uma mesma configuração de mão com sentido referente a um monitor/tela.
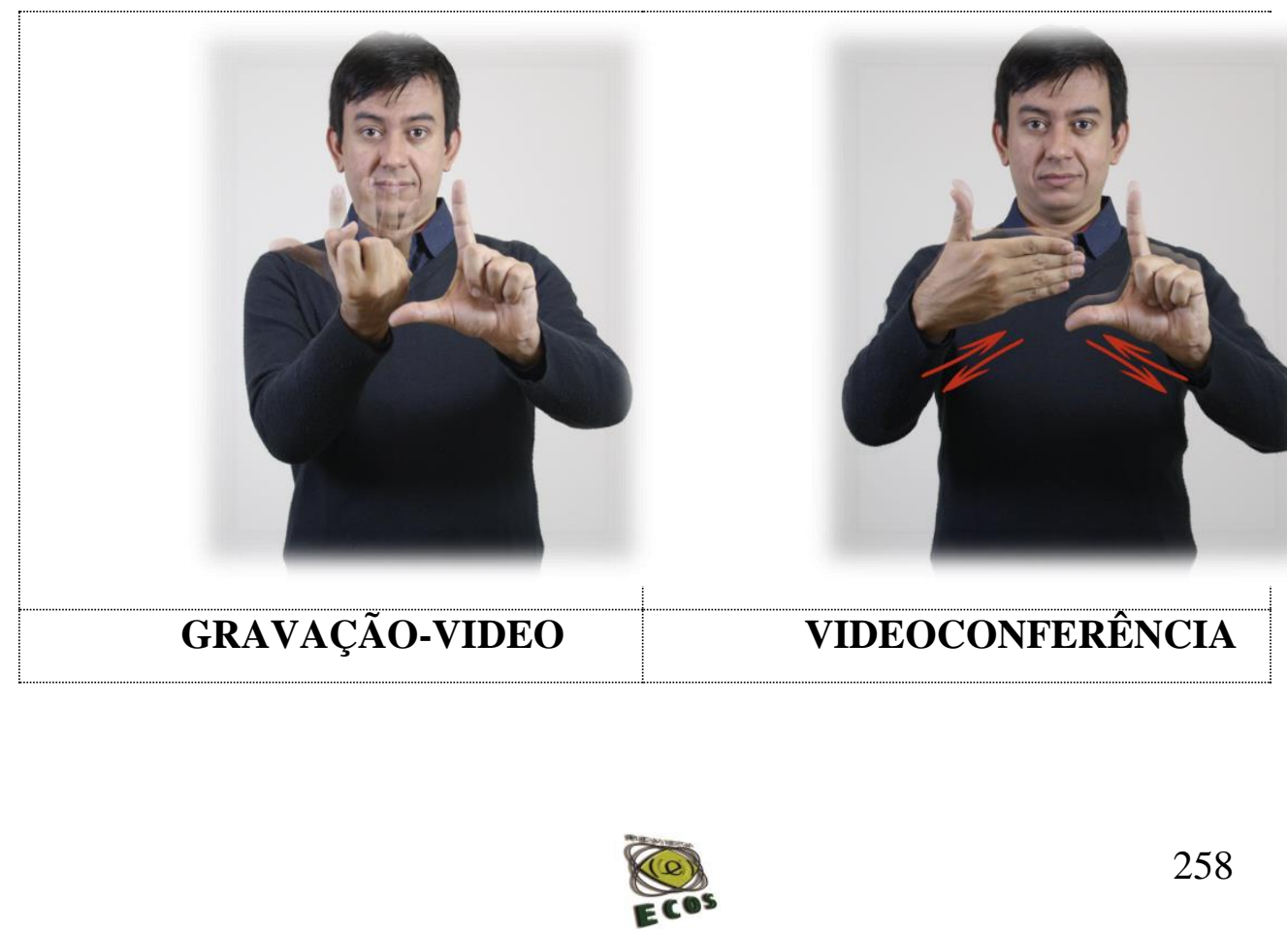
ISSN: 2316-3933

Online

\section{REVISTA ECOS}

Programa de Pós-graduação em Estudos Literários/ UNEMAT

Programa de Pós-graduação em Linguística/ UNEMAT

Centro de Estudos e Pesquisas em Literatura

Centro de Estudos e Pesquisas em Linguagem
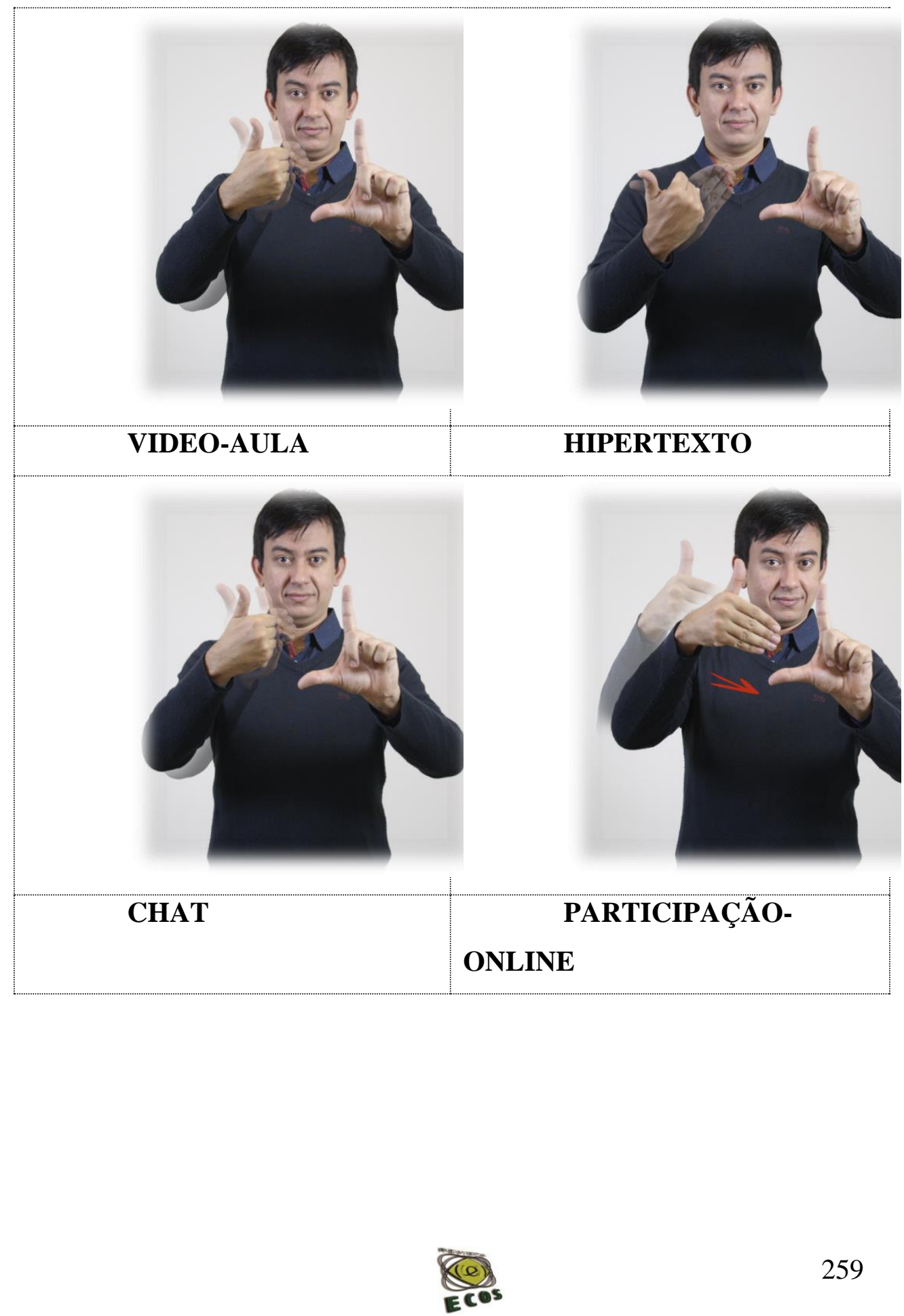
ISSN: 2316-3933

Online

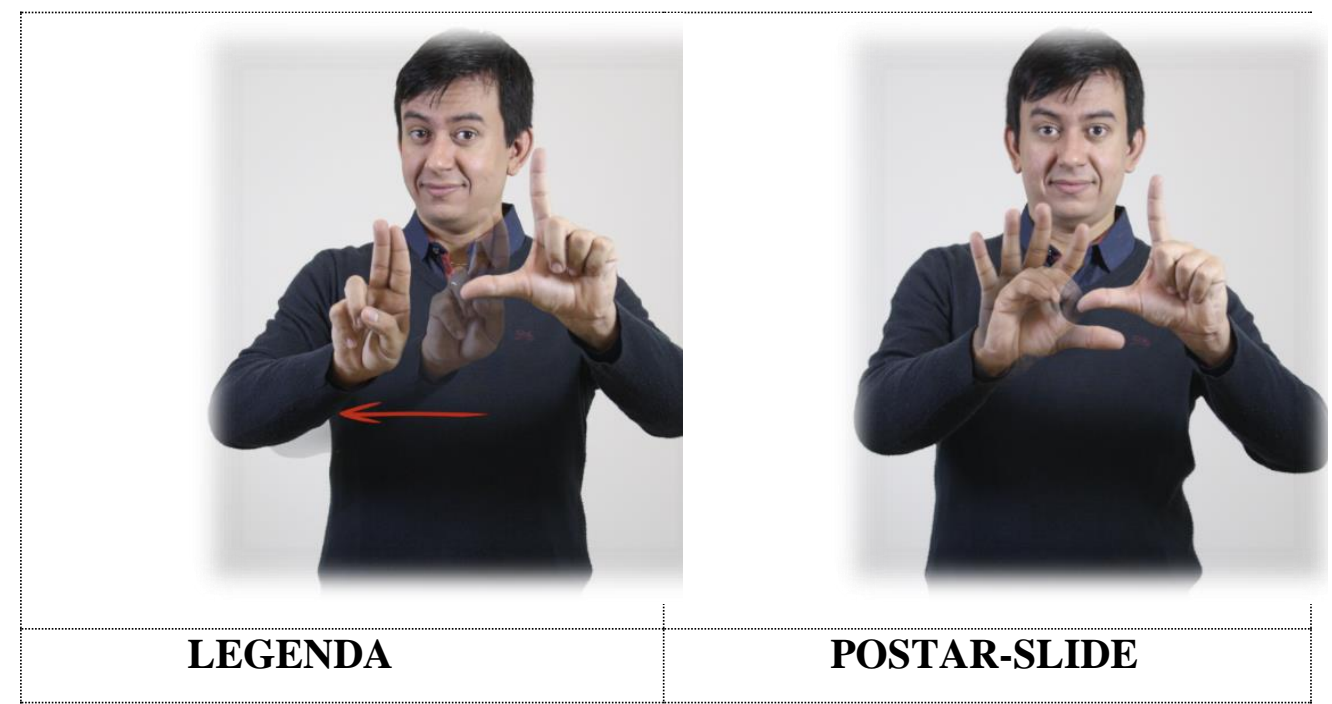

Por fim, segue uma família lexical que possui em comum uma mesma configuração de mão e movimento. $\mathrm{O}$ sentido desse grupo é atribuído a ideia de formação acadêmica (diploma/título).
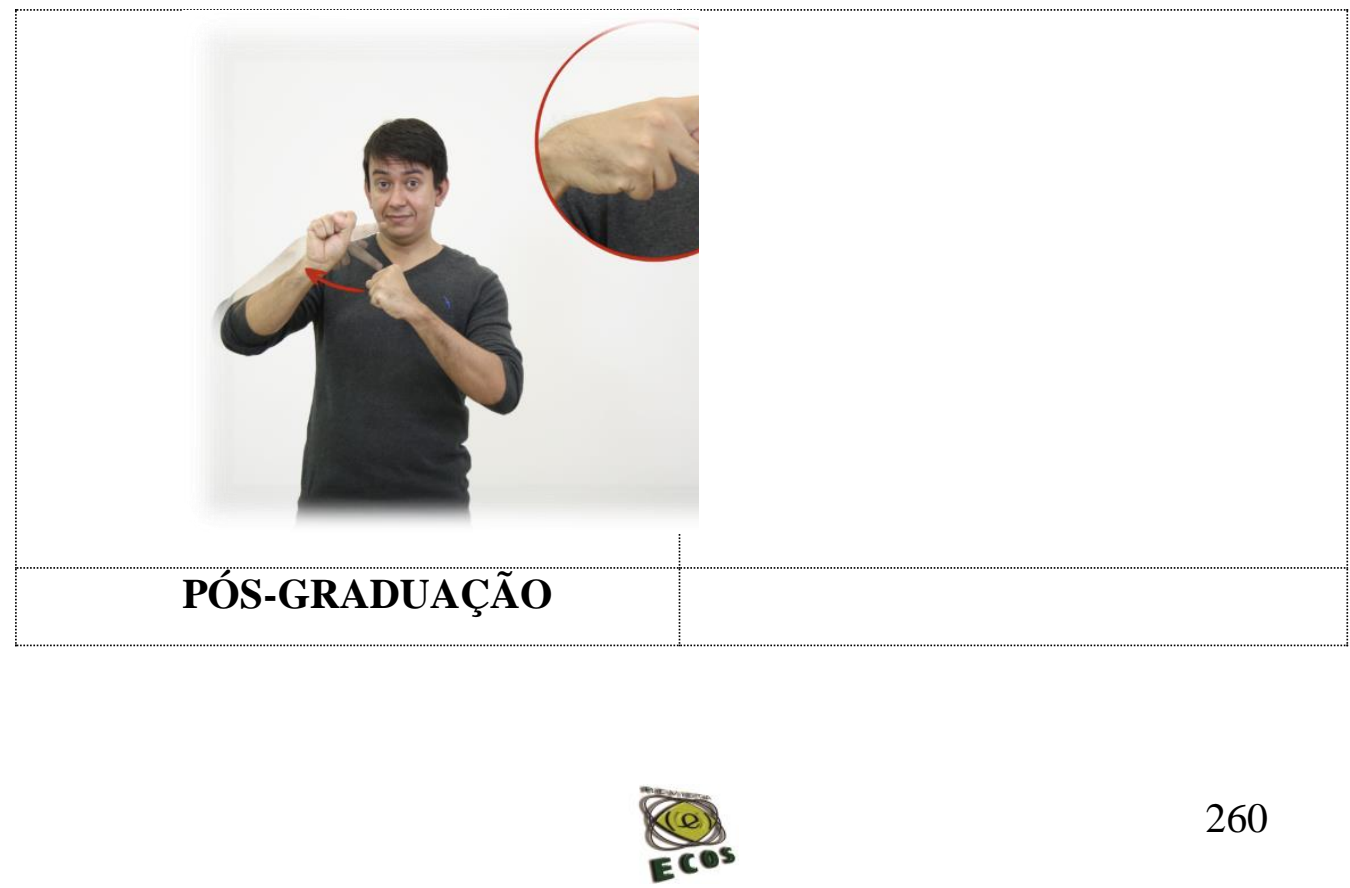


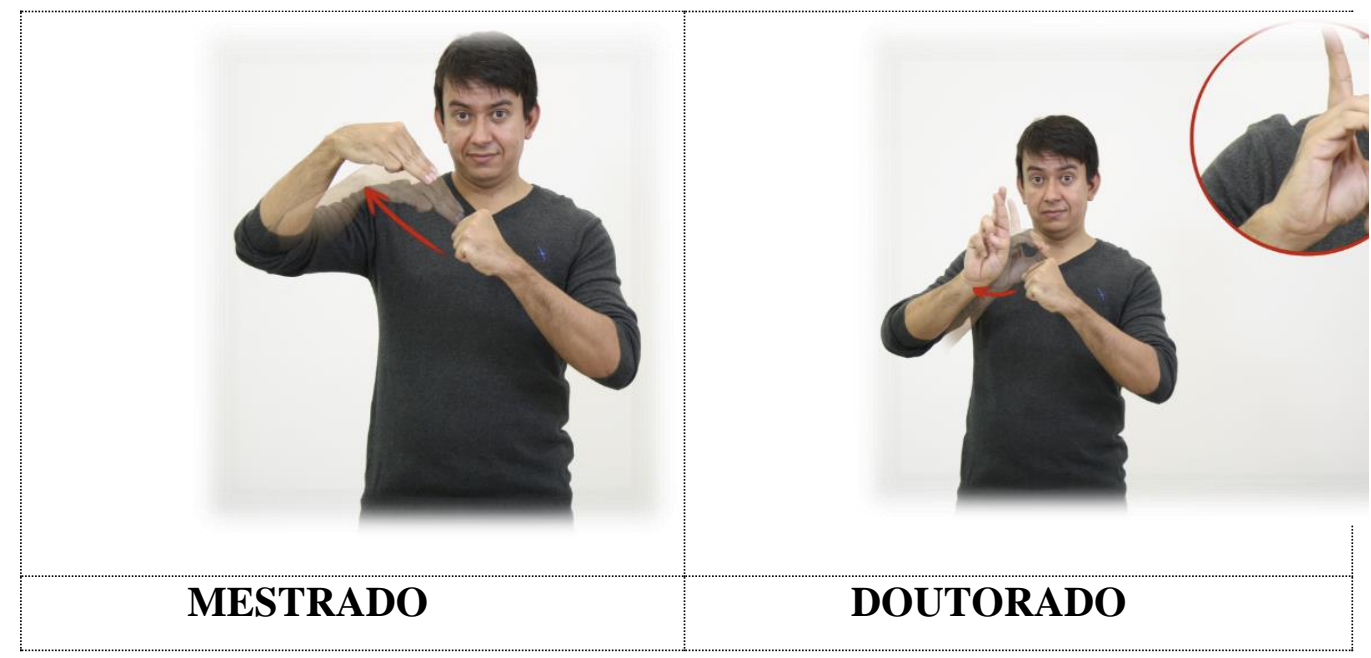

Após a apresentação dessas famílias lexicais, evidencia-se que na Libras também podemos encontrar os fonestemas, ou seja, existe uma relação semântica e fonológica (articuladores visuais) a partir de uma mesma base linguística que se repete em alguns signos, conforme aponta estudos feitos em línguas orais (ABELIN, 1999).

Esses fonestemas são considerados, segundo Ullmann (1962), elementos menores que os morfemas, que possuem iconicidade secundária, pelo fato de não conterem um referente específico capaz de trazer a significação ou referenciação plena como acontece com signos que possuem iconicidade primária. Na Libras, um clássico exemplo de iconicidade primária é o sinal ÁRVORE, já que esse lexema é expresso pela representação e caracterização visual do objeto. 


\section{Considerações finais}

Pesquisas que envolvam os fonestemas nas línguas orais já são difundidas no cenário internacional. Contudo, em relação às línguas de sinais, ainda existe uma lacuna de estudos que discutam as interlocuções sigmanulogia e semânticas na constituição de signos. Por se tratar de línguas naturais, acreditamos na existência desse fenômeno.

Por fim, esse trabalho traz considerações ainda iniciais sobre essa temática, mas que viabiliza uma gama de possibilidades para a compreensão e avanços no que tange a linguística teórica e descritiva como a lexicologia, lexicografia e linguística aplicada ao ensino da Língua Brasileira de Sinais, bem como incentivar a reflexão de novos pesquisadores para essa área.

\section{Referências}

ABELIN, A. Studies in Sound Symbolism, Goteborg University, Goteborg, Sweden, 1999.

BLOOMFIELD, L. Language. New York: Holt, Rinehart and Winston, 1961 (1933).

CRUSE, D. A. Lexical semantics. Melbourne: Cambridge University Press, 1986.

HEALY, C. Pinky. Extension as a phonestheme in Mongolian Sign Language. Sign Language Studies, v.11, n.4, 2011, p. 575-593.

LYONS, J. Semantics. Melbourne: Cambridge University Press, v. 1, 1984. 
MINAYO, M. C. S. (Org.). Pesquisa social: teoria, método e criatividade.

Petrópolis: Vozes, 2001.

MORENO, J. B. Importancia de los fonestemas en el campo fonéticofonológico y morfológico. Língua Americana Año III, n.9, 1999, p. 59-70.

NÓBREGA, V. R. R. Sigmanulogia: proporcionado uma teoria linguística da língua de sinais. Revista Leitura, v.1, n.57, p.198-218, 2016.

RATHMANN, C.; MATHUR, G. Sign Morphology. Washighton D.C: Gallaudet University, 2010?, p. 1-32.

SAUSSURE, F. Curso de linguística geral. São Paulo: Cultrix, (1991 (1916)).

ULLMANN, S. Semântica: uma introdução à ciência do significado. Lisboa: Fundação Calouste Gulbenkian, 1977 (1964).

WEEDWOOD, B. História concisa da linguística. Tradução: Marcos Bagno. São Paulo: Parábola, 2005. 